\title{
Plasmid diversity in Vibrio vulnificus biotypes
}

\section{Correspondence \\ Carmen Amaro \\ carmen.amaro@uv.es}

Received 18 August 2008

Revised 27 October 2008

Accepted 4 November 2008

\section{Francisco J. Roig and Carmen Amaro}

Department of Microbiology and Ecology, Faculty of Biology, University of Valencia, Dr. Moliner 50, 46100 Burjassot, Valencia, Spain

\begin{abstract}
Vibrio vulnificus is a heterogeneous bacterial species that can be virulent for humans and fish. Virulence in fish seems to rely on a recently described plasmid that can be transmitted between strains, aided by a conjugative plasmid. The main objective of this work was to analyse the plasmid content of a wide collection of strains from the three biotypes of the species, as well as to identify putative conjugative and virulence plasmids by means of Southern hybridization with specific probes and sequence analysis of selected gene markers. We found 28 different plasmid profiles in a total of 112 strains, which were relatively biotype- or serovar-specific. Biotype 1 lacked highmolecular-mass plasmids, with the exception of a putative conjugative plasmid of $48 \mathrm{~kb}$ that was present in $42.8 \%$ of clinical and environmental strains isolated worldwide. All biotype 2 strains possessed the virulence plasmid, whose molecular mass ranged between 68 and $70 \mathrm{~kb}$, and $89.65 \%$ of these strains also had a putative conjugative plasmid with a molecular size of 52$56 \mathrm{~kb}$. Finally, a $48 \mathrm{~kb}$ putative conjugative plasmid was present in all biotype 3 strains. Data from partial sequencing of $\mathrm{tra}$, tral and the whole vep07 (a recently described plasmid-borne virulence gene) from a selection of strains suggest that the plasmids of 48-56 kb probably belong to the same family of F-plasmids as pYJ016 and that the gene vep07 is absolutely essential for fish virulence. Additional cryptic plasmids of low molecular mass were present in the three biotypes. In conclusion, plasmids are widespread among V. vulnificus species and could contribute substantially to genetic plasticity of the species.
\end{abstract}

\section{INTRODUCTION}

Vibrio vulnificus is a heterogeneous aquatic species that has been subdivided into biotypes and serovars (Tison et al., 1982; Bisharat et al., 1999, 2007b). Biotypes 1 and 2 include environmental and clinical isolates recovered worldwide, while biotype 3 comprises solely clinical isolates from Israel (Oliver, 2006). Biotypes 1 and 2 are serologically diverse, whereas biotype 3 is serologically homogeneous (Amaro et al., 1992; Bisharat et al., 2007a, b; Fouz et al., 2007). Three O-serovars have been described in biotype 2 (serovar A, serovar E, serovar I), one in biotype 3 (serovar O), and more than four in biotype 1 , which has not been fully serotyped (Biosca et al., 1996; Fouz et al., 2007; Bisharat et al., 2007a; Amaro et al., 1992).

The three biotypes of $V$. vulnificus can cause disease in humans following ingestion of contaminated seafood or immersion exposure of an open wound to contaminated seawater (Oliver, 2005, 2006). In relatively healthy people, ingestion of or exposure to V. vulnificus leads to vomiting, diarrhoea and wound infection or severe ulceration, while in immunocompromised individuals, particularly those

Abbreviations: BCIP, 5-bromo-4-chloro-3-indolyl phosphate; NBT, nitro blue tetrazolium chloride; SSC, citrate buffer.

The GenBank/EMBL/DDBJ accession numbers for the sequences resulting from the PCRs in this study are FJ000003-FJ000061. with chronic liver disease, the pathogen can invade the bloodstream and cause septicaemia and death in almost $50 \%$ of cases (Oliver, 2005, 2006). Biotype 2 also causes a disease called warm-water vibriosis in fish (mainly eels) and shrimp (Tison et al., 1982). The strains of this biotype with pathogenic potential for humans belong to serovar E (Amaro \& Biosca, 1996).

Recently, the genomes of two human biotype 1 isolates from Asia have been sequenced in Taiwan and South Korea (Chen et al., 2003; Kim et al., 2003). A comparison of these genomes revealed that the two strains share approximately $98 \%$ of the chromosomal information, differing mainly in their plasmid content. For example, one of the strains (strain YJ016) possesses a conjugative plasmid of $48 \mathrm{~kb}$, which is absent in the other isolate (Chen et al., 2003; Kim et al., 2003). Previous studies on plasmid carriage in $V$. vulnificus found these extrachromosomal elements to be rare within the species (Davidson \& Oliver, 1986), with the exception of biotype 2 isolates, which appear to possess plasmids of high molecular mass (Biosca et al., 1996; Lee et al., 2008; Lewin et al., 2000). One of these plasmids, $68 \mathrm{~kb}$ in size, seems to be a virulence plasmid essential for fish vibriosis since inactivation in one serovar $\mathrm{E}$ isolate resulted in a loss of resistance to eel serum, and thus was avirulent for eels (Lee et al., 2008; Valiente et al., 2008). This plasmid can be transmitted between strains, aided by a conjugative 
plasmid of $56 \mathrm{~kb}$, by cointegrate formation (Lee et al., 2008). The virulence plasmids of two biotype 2 serovar $E$ strains show $92 \%$ homology (Lee et al., 2008) and contain two sequences, seq 25 and seq 51 , that have previously been found, by subtractive hybridization, to be specific to eelvirulent strains and are associated with vep07, an ORF with an essential role in eel virulence (mutations in this gene produce the same effect as inactivation of the plasmid) (Lee et al., 2008). This ORF codes for a novel protein with low similarity to a toxin of the family of RTX toxins (Lee et al., 2008).

The aim of this work was to study the distribution of the virulence and conjugative plasmid, together with cryptic plasmids, among $V$. vulnificus biotypes and serovars, using probes derived from selected genetic markers for virulence and conjugative plasmids. The vep07 ORF was sequenced in a selection of virulence plasmids and the sequences were compared in order to obtain information on the evolution of the virulence plasmid within this species.

\section{METHODS}

Bacterial strains and growth conditions. The V. vulnificus strains used in this study are listed in Table 1. Escherichia coli was routinely grown in Luria-Bertani broth (LB) or agar (LBA) (Pronadisa) and $V$. vulnificus strains were grown in Tryptone Soy Broth or agar plus $5 \mathrm{~g}$ $\mathrm{NaCl}^{-1}$ (TSB-1 or TSA-1, Pronadisa) at $28{ }^{\circ} \mathrm{C}$ for $24 \mathrm{~h}$. For plasmid extraction, bacteria were grown in LB or TSB-1 for 4-6 h, and for genomic DNA extraction, they were grown overnight, in both cases with shaking at $28{ }^{\circ} \mathrm{C}$. The strains were maintained both as lyophilized stocks and as frozen stocks at $-80{ }^{\circ} \mathrm{C}$ in marine broth (Difco) plus $20 \%(\mathrm{v} / \mathrm{v})$ glycerol.

DNA extractions and electrophoretic analysis. Genomic DNA was extracted according to the mini-prep protocol for genomic DNA extraction (Ausubel et al., 2007). Plasmid DNA was extracted by following the TENS protocol (Zhou et al., 1990) with minor modifications, which included using a volume of $200 \mu \mathrm{l}$ sodium acetate $(3 \mathrm{M}, \mathrm{pH} 4.8)$ followed by a $10 \mathrm{~min}$ incubation on ice and reduction of the volume and number of phenol/chloroform/isoamyl alcohol $(25: 24: 1)$ extractions. After dissolving DNA at $37^{\circ} \mathrm{C}$ for $2 \mathrm{~h}$, samples were subjected to electrophoresis on $0.7 \%(\mathrm{w} / \mathrm{v})$ agarose gels (Roche, molecular grade) for $3 \mathrm{~h}$ at $50 \mathrm{~V}$. Plasmid molecular sizes were estimated using several reference plasmids: E. coli V517 (plasmids of 54.38, 7.30, 5.56, 5.14, 3.98, 3.08, 2.06, $2.71 \mathrm{~kb}$ ) and $E$. coli 39R861 (plasmids of 154, 66.2, 37.6, $7.4 \mathrm{~kb}$ ) (Macrina et al., 1978; Threlfall et al., 1986). Plasmid extraction and molecular size determinations were done in triplicate. Strains were grouped according to their plasmid profiles.

PCR and sequence analysis. PCR was performed to detect and sequence the virulence plasmid markers seq51 and seq25 (Lee et al., 2005), the conjugative plasmid markers traD, traI and traI2, as well as the whole gene vep07, using the primers listed in Table 2 . The reaction mixtures $(50 \mu \mathrm{l})$ for PCR contained $1.2 \mu \mathrm{l}$ of each primer $(10 \mathrm{mM})$,

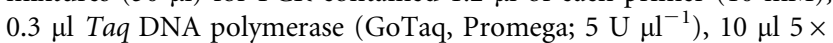
Taq reaction buffer (Promega, Gotaq Green), $3.0 \mu \mathrm{l} 50 \mathrm{mM} \mathrm{MgCl}$, $0.5 \mu \mathrm{dNTP}$ mix (Promega, $10 \mathrm{mM}$ of each) and $2 \mu \mathrm{l}$ template DNA $\left(50 \mathrm{ng} \mu \mathrm{l}^{-1}\right)$. The PCR was performed in a Techne thermocycler (TC412). The reaction started with $10 \mathrm{~min}$ denaturation at $94{ }^{\circ} \mathrm{C}$, followed by 45 cycles of $40 \mathrm{~s}$ denaturation at $94{ }^{\circ} \mathrm{C}, 45 \mathrm{~s}$ annealing at the primer-specific temperature shown in Table 2 and $45 \mathrm{~s}$ extension at $72{ }^{\circ} \mathrm{C}$ ( $90 \mathrm{~s}$ for amplification of the vep07 gene); an additional extension at $72{ }^{\circ} \mathrm{C}$ for $10 \mathrm{~min}$ completed the reaction. A negative control (no template DNA) and a positive control (purified DNA of the serovar E strain CECT 4604) were included in each PCR batch. The amplified products were separated by electrophoresis at $100 \mathrm{~V}$ for $30 \mathrm{~min}$ on a $2 \%(\mathrm{w} / \mathrm{v})$ agarose (Low EEO, Pronadisa) gel in TAE buffer (Real) and were visualized by staining with ethidium bromide.

PCR products were sequenced with the ABI 3730 (Applied Biosystems) and the BigDye Terminator v3.1 Cycle Sequencing kit protocol (Applied Biosystems). Oligonucleotides were purchased from Invitrogen. The resulting sequences were deposited in GenBank (accession nos FJ000003-FJ000061). A multiple sequence alignment was performed using AlignX (Invitrogen) and the evolutionary history for each gene, or gene fragment, was inferred using the neighbour-joining method (Saitou \& Nei, 1987). The evolutionary distances were computed using the Poisson correction method (Zuckerkandl \& Pauling, 1965), expressed as the number of amino acid substitutions per site. All positions containing alignment gaps and missing data were eliminated in pairwise sequence comparisons only. Phylogenetic analyses were conducted in MEGA4 (Tamura et al., 2007).

Southern hybridization. To localize the marker sequences in the plasmids, Southern hybridization was performed using PCR-labelled amplified products as probes, which were generated by adding $0.15 \mu \mathrm{l}$ of $10 \mathrm{mM}$ digoxigenin-11-dUTP (Roche) to the PCR mixture. Plasmid DNA was transferred to the membranes (Zeta-probe blotting membrane, Bio-Rad) with a Vacuum Blotter model 785 (Bio-Rad) following the manufacturer's instructions. Hybridization was performed using the DIG Easy Hyb Granules kit (Roche) according to the manufacturer's instructions. The hybridization solution was removed and membranes were washed $2 \times 5 \mathrm{~min}$ in $2 \times$ SSC containing $0.1 \%$ SDS at room temperature, $2 \times 15 \mathrm{~min}$ in $0.5 \times$ SSC containing $0.1 \%$ SDS at $65{ }^{\circ} \mathrm{C}$, and $2 \times 15 \mathrm{~min}$ in $0.1 \times \mathrm{SSC}$ containing $0.1 \%$ SDS at $68{ }^{\circ} \mathrm{C}$. Anti-digoxigenin-AP, Fab fragments and Blocking reagent (Roche) were used for development, following the manufacturer's instructions. Membranes were incubated in detection buffer (100 mM Tris/HCl, $100 \mathrm{mM} \mathrm{NaCl}, \mathrm{pH}$ 9.5; $\mathrm{MgCl}_{2}$ to $50 \mathrm{mM}$ ) for $5 \mathrm{~min}$ followed by incubation in coloured buffer

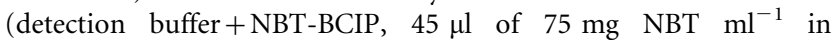

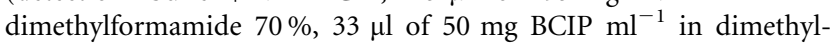
formamide $100 \%$ and $10 \mathrm{ml}$ detection buffer) without light at room temperature for 12-24 h. Finally, membranes were washed twice in distilled water for $2 \mathrm{~min}$, dried and photographed. Plasmid extraction of E. coli 39R861, labelled with the Dig-high prime kit (Roche) according to the manufacturer's instructions, was used as a reference to distinguish the positive V. vulnificus plasmids for each probe.

Eel virulence. Strains tested for virulence are marked in Table 1. Juvenile European elvers (mean weight $10 \mathrm{~g}$ ) were maintained in aquaria containing 91 water $\left[0.5 \%(\mathrm{w} / \mathrm{v})\right.$ salinity] at $25^{\circ} \mathrm{C}$. A bacterial dose of $10^{6}$ c.f.u. per animal was intraperitoneally injected in groups of six animals and mortalities were recorded daily for a 7 day period. A strain was considered virulent if mortality exceeded $50 \%$ (Amaro et al., 1995). Mortalities were only considered to be caused by $V$. vulnificus if the inoculated bacterium was recovered as a pure culture from internal organs. Two groups of animals were challenged with saline solution $(0.9 \% \mathrm{NaCl}, \mathrm{pH} 7.0)$ and included as negative controls. For each V. vulnificus strain tested, the $\mathrm{LD}_{50}$ was calculated according to Reed \& Muench (1938).

Ribotyping. Representative isolates of each plasmid profile were genetically analysed by automated ribotyping with a Riboprinter (Qualicon). Ribotyping was performed under the conditions recommended by the manufacturer, except that EcoRI was replaced by HindIII (Roche) (400 U $\mathrm{I}^{-1}$ in standardized reagents in $1.5 \mathrm{ml}$ tubes). Each isolate was ribotyped twice. 
Table 1. Plasmid profile, biotype, serovar and source of the $V$. vulnificus strains used in this study

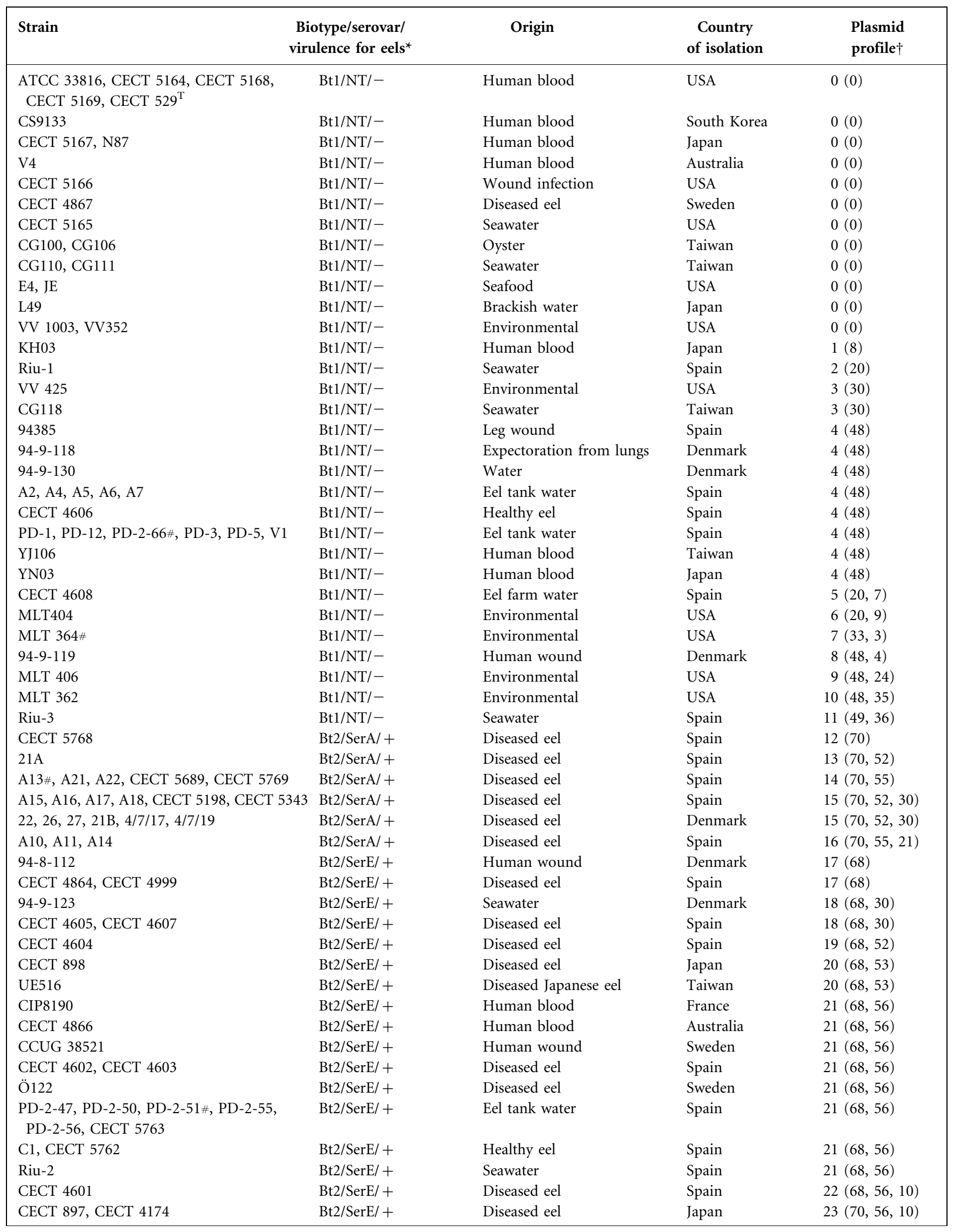


Table 1. cont.

\begin{tabular}{|c|c|c|c|c|}
\hline Strain & $\begin{array}{c}\text { Biotype/serovar/ } \\
\text { virulence for eels* }\end{array}$ & Origin & $\begin{array}{c}\text { Country } \\
\text { of isolation }\end{array}$ & $\begin{array}{l}\text { Plasmid } \\
\text { profile } \dagger\end{array}$ \\
\hline CECT 4865 & Bt2/SerE/ + & Diseased shrimp & Taiwan & $24(68,56,30)$ \\
\hline CECT 4868 & $\mathrm{Bt} 2 / \mathrm{SerE} /+$ & Diseased eel & Norway & $24(68,56,30)$ \\
\hline $90-2-11$ & $\mathrm{Bt} 2 / \mathrm{SerE} /+$ & Diseased eel & Denmark & $24(68,56,30)$ \\
\hline CECT 4862 & $\mathrm{Bt} 2 / \mathrm{SerE} /+$ & Diseased eel & Japan & $\begin{array}{l}25(70,52,34, \\
20)\end{array}$ \\
\hline $95-8-161,95-8-162$ & Bt2/SerI/ + & Diseased eel & Denmark & $26(70,55,5)$ \\
\hline CECT 4869\# & Bt2/SerI/- & Diseased eel & Belgium & $\begin{array}{l}27(70,54,34 \text {, } \\
5)\end{array}$ \\
\hline $95-8-6,95-8-7$ & Bt2/SerI/ + & Diseased eel & Denmark & $\begin{array}{l}27(70,54,34 \text {, } \\
5)\end{array}$ \\
\hline $97,162,11028, \mathrm{vv} 12, \mathrm{vv} 32$ & $\mathrm{Bt} 3 / \mathrm{SerO} /-$ & Diseased human & Israel & $28(48,5)$ \\
\hline
\end{tabular}

${ }^{\star}$ Bt, biotype; NT, non-typable; SerE, serovar E; SerA, serovar A; SerI, serovar I; SerO, serovar O. Data on serology and virulence from Lee et al. (2005), Fouz et al. (2007) and from this work (strains marked \# in column 1).

$\dagger$ The molecular mass of the plasmids is indicated in parentheses.

$\ddagger$ Spontaneous mutant in vep07.

\section{RESULTS}

\section{Plasmid profiles}

A total of 28 plasmid profiles were found in the 112 analysed strains (Table 1). Biotype 1 strains produced 12 different profiles, biotype 2 produced 14, and biotype 3 possessed a unique profile. Of the biotype 1 strains, $42.8 \%$ lacked plasmids (profile 1), and an identical percentage possessed a plasmid similar in size to the conjugative plasmid pYJ106 (47-48 kb). A plasmid of around $30 \mathrm{~kb}$ was recorded in $8.6 \%$ of biotype 1 strains, while a $20 \mathrm{~kb}$ plasmid was found in $6.8 \%$, and a plasmid of between 3 and $8 \mathrm{~kb}$ in $8.6 \%$ of these strains (Table 1). All biotype 2 strains possessed a plasmid of molecular size similar to the virulence plasmid described in strains CECT 4999 and CECT 4602 (68-70 kb) (Lee et al., 2008) and $88 \%$ possessed a second plasmid of a molecular size similar to the conjugative plasmid p4602-1 (52-56 kb). In addition, $22.4 \%$ of biotype 2 strains possessed a plasmid of around $30 \mathrm{~kb}, 6.9 \%$ had a plasmid of $20 \mathrm{~kb}$, and $13.8 \%$ a plasmid of between 5 and $10 \mathrm{~kb}$ (Table 1). The profile generated by biotype 3 strains corresponded to a plasmid of $48 \mathrm{~kb}$ and a second plasmid of $5 \mathrm{~kb}$ (Table 1 ).

Table 2. Oligonucleotides used in this study to analyse plasmid diversity

\begin{tabular}{|c|c|c|c|c|}
\hline Primer & Sequence & $\begin{array}{l}\text { Annealing } \\
\text { temp. }\left({ }^{\circ} \mathrm{C}\right)\end{array}$ & $\begin{array}{l}\text { Size } \\
(\mathbf{b p})\end{array}$ & Use \\
\hline Seq25F & TGCTCAAAGCCATACTCTCT & 52 & 411 & Marker for virulence plasmid \\
\hline Seq25R & GCCAAGTGCTAATCCATCC & & & \\
\hline Seq51F & AGAGATGGAAGAAACAGGCG & 52 & 344 & Marker for virulence plasmid \\
\hline Seq51R & GGACAGATACAAGGGCAAATGG & & & \\
\hline TraIF & CTGAGCACCACACCAAGGC & 52 & 652 & Marker for conjugative plasmid \\
\hline TraIR & CGTGTACGCTGTTGTCCCT & & & \\
\hline TraI2F & GAAGCGAGACGATCACAA & 54 & 782 & $\begin{array}{l}\text { Marker for virulence/conjuga- } \\
\text { tive plasmid }\end{array}$ \\
\hline TraI2R & AGTGGTCAATCGCTCTGCTG & & & \\
\hline TraDF & CACCAGTAAGTTCTTCGACC & 53 & 619 & $\begin{array}{l}\text { Marker for virulence/conjuga- } \\
\text { tive plasmid }\end{array}$ \\
\hline TraDR & CTCGTCCATAATCACCCAGA & & & \\
\hline Vep07F & TCTCCTCTAGGCGATTACCG & 50.2 & 1494 & $\begin{array}{l}\text { Primers to sequence the vep07 } \\
\text { gene }\end{array}$ \\
\hline Vep07R & CACCCGAATTAATCAGC & & & \\
\hline
\end{tabular}


Table 3. Changes in vep07 in the spontaneous mutant CECT 4869

\begin{tabular}{|lcccc|}
\hline & \multicolumn{3}{c|}{ Changes in nt } & \multirow{2}{*}{ Amino acid sequence from residue 80 } \\
\cline { 2 - 4 } & $\mathbf{2 9 3 - 2 9 4}$ & $\mathbf{2 6 8}$ & $\mathbf{2 6 3}$ & \\
\hline Seq51 CECT 4869 & AA & $\star$ & A & ...DQELIRTDIRQMEILEAANLLALMESY $\dagger$ \\
Seq51 GenBank AY691409 & TT & C & G & ...DQELIRTDTRANGNFGSSISVSSNGKLLVVSAAQNTPSEGKK... \\
\hline
\end{tabular}

${ }^{\star}$ Point deletion.

$\dagger$ Stop codon.

\section{Plasmid analysis}

Identification of the virulence plasmid for eels. First, a PCR was conducted with all the strains to confirm that the virulence plasmid was present in all biotype 2 strains and absent in all biotype 1 and 3 strains. A PCR product of the predicted size was found by PCR with primers Seq25FR and Seq51FR in all biotype 2 strains (profiles 13-27) with the exception of the serovar I strain CECT 4869, which was positive for seq25 but negative for seq51. Additional PCRs were performed with primer Seq51FR for this strain, decreasing the annealing temperature to $40{ }^{\circ} \mathrm{C}$, and a PCR product of the correct size was obtained. This product was sequenced and compared with the database (Lee et al., 2005) and the differences detected are shown in Table 3. seq51 is located within vep07, a virulence gene (GenBank accession no. FJ000051). The whole gene was sequenced in strain CECT 4869 and in a selection of biotype 2 strains (one for each plasmid profile group). The gene showed $100 \%$ homology for the majority of the strains with the exception of four isolates: CECT 4601 and 94-9-112, which had a non-coding change at position 120 ( $\mathrm{G}$ instead of T), and CECT 5769 and 95-8-161, which had one amino acid substitution at position 171 (arginine for glycine). The distance tree for the vep07 protein is shown in Fig. 1. All the strains with homology between $99.7 \%$ and $100 \%$ for vep07 were virulent for eels (percentage mortalities after injection of $10^{6}$ c.f.u. per fish greater than $50 \%$ ) (Table 1). The strain CECT 4869, which produces a different protein, was avirulent for eels by

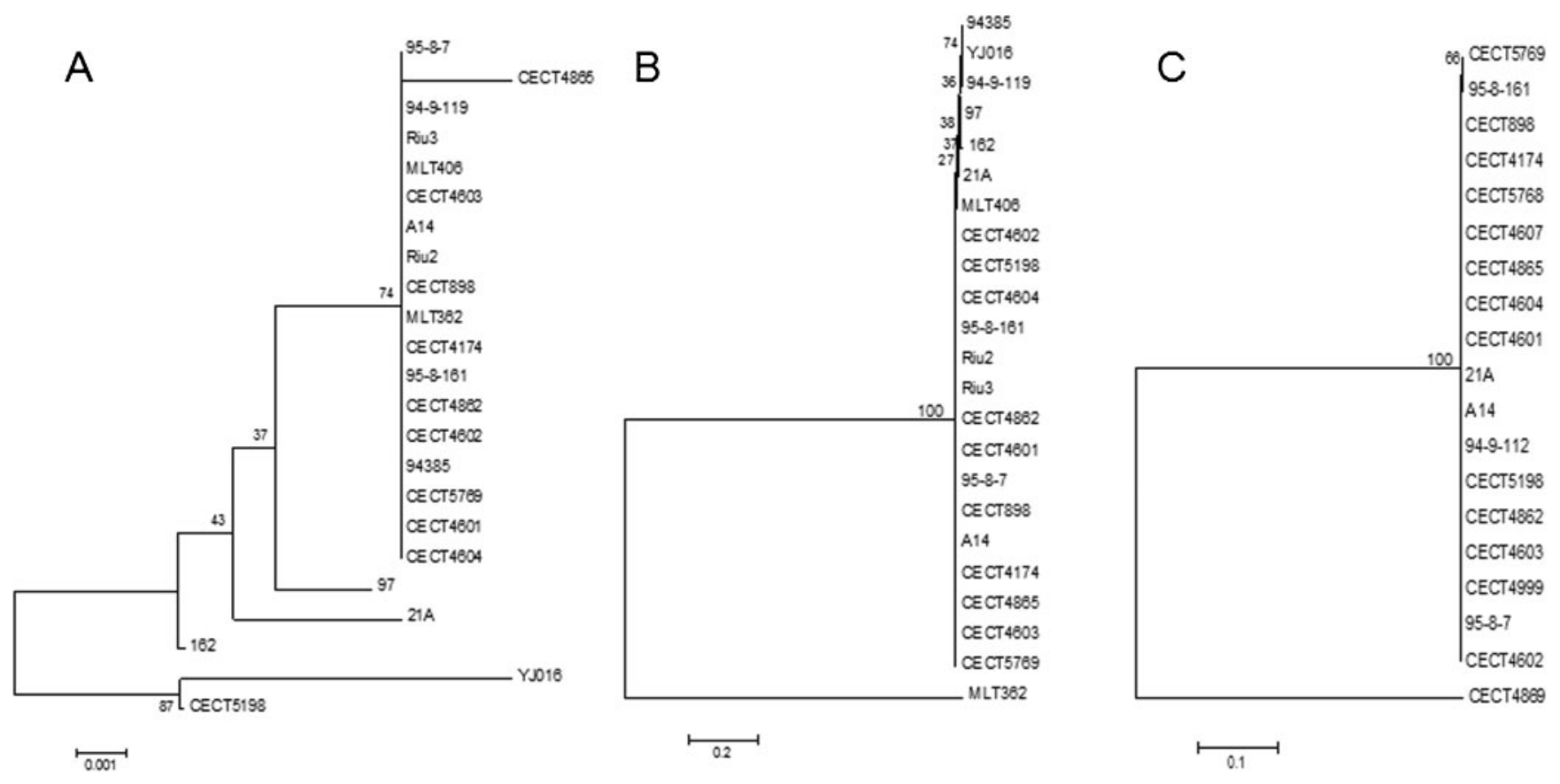

Fig. 1. Neighbour-joining dendrogram for the V. vulnificus isolates based on variation in a fragment of TraD (A) and Tral (B) and the whole protein Vep07 (C). The percentage of replicate trees in which the associated taxa clustered together in the bootstrap test (1000 replicates) is shown next to the branches (Felsenstein, 1985). The trees are drawn to scale, with branch lengths in the same units as those of the evolutionary distances used to infer the phylogenetic tree. The bar indicates the relative sequence divergence. 


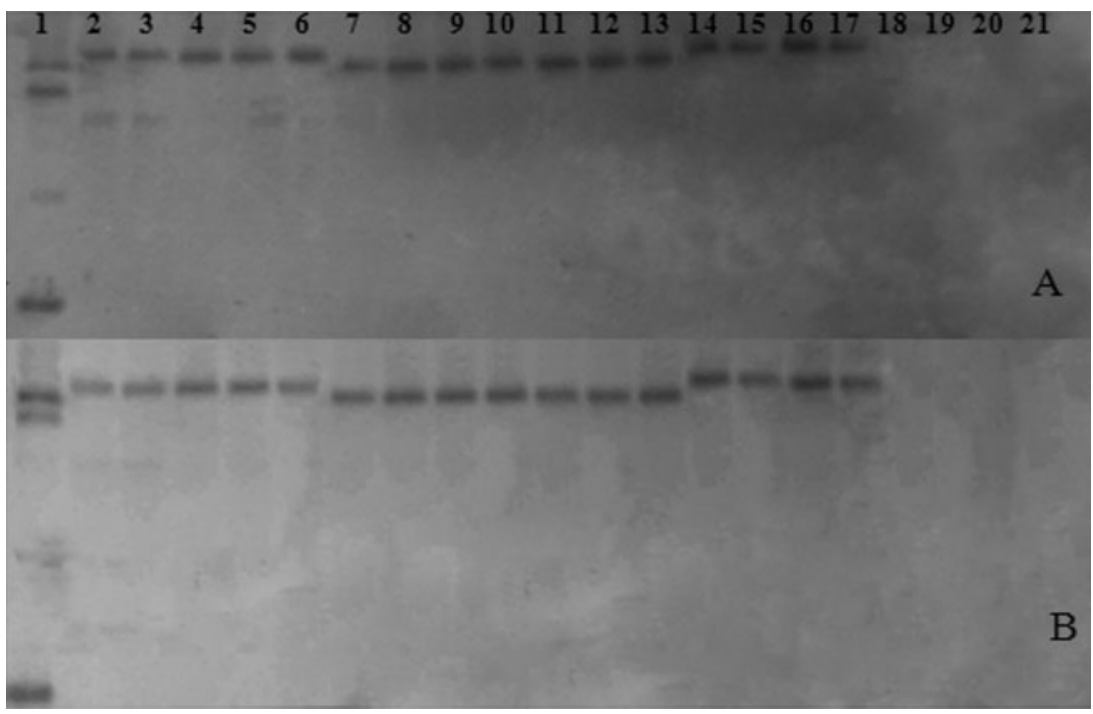

Fig. 2. Southern hybridization with probes Seq25 (A) and Seq51 (B). Lanes: 1, prestained 39R861 (see Methods); 2, CECT 5198; 3, CECT 5768; 4, CECT 5769; 5 , $\mathrm{A} 14 ; 6,21 \mathrm{~A} ; 7,94-8-112 ; 8,94-9-123 ; 9$, CECT 4602; 10, CECT 898; 11 , CECT 4604; 12, 90-2-11; 13, CECT 4601; 14, CECT 897; 15, CECT 4862; 16, 95-8-161; 17, 95-8-6; 18, YJ016; 19, CG100; 20, 11028; 21,VV12.

intraperitoneal injection since none of the fish died after injection of $10^{6}$ c.f.u. per fish 7 days post-infection (Table 1).

The plasmid carrying seq25 and seq 51 was identified by hybridization with probes derived from the amplified products. In all cases, only the plasmid of the highest molecular mass $(68-70 \mathrm{~kb})$ hybridized with the probes (Fig. 2). None of the biotype 1 and biotype 3 plasmids hybridized with the probes from eel virulence markers and none of the strains were virulent for eels (Table 1).

Identification of the conjugative plasmid. The primer pairs $\mathrm{TraDR} / \mathrm{F}, \mathrm{TraIR} / \mathrm{F}$ and $\mathrm{TraI} 2 \mathrm{R} / \mathrm{F}$ were designed to detect the traD, traI and traI' genes. The traI' gene is a non-functioning truncated pseudogene present in virulence plasmids pR99 and pC4602-1 (Lee et al., 2008).

Fig. 3 shows the regions in which the primers annealed and their derived probes. Three PCR products of the predicted size were obtained in strains with the plasmid profiles $4,8-$ $11,13-16$ and 19-28, regardless of biotype or serovar, whereas a unique PCR product of the predicted size was obtained with primers TraI2F/R in strains corresponding to plasmid profiles 12 and 17 (data not shown). Based on the primer design, only plasmids that hybridized with all the probes could be considered as conjugative. Plasmids of 48-49 kb present in biotype 1 strains (profiles 5 and 9-12), the biotype 3 strain (profile 28), as well as the plasmids of 52-56 kb present in biotype 2 strains (profiles $14-17$ and 20-27) hybridized with all three probes and were identified as putative conjugative plasmids (Fig. 3). Biotype 2 plasmids of molecular size $68-70 \mathrm{~kb}$ hybridized with the TraI2 probe, but not with the TraI probe (Fig. 3).

The presence of traD and traI was further confirmed by sequence analysis of the PCR products of selected positive strains from each plasmid profile group. In Fig. 1 the distance tree for a fragment of the proteins $\mathrm{TraD}$ and TraI is shown. The similarity of these protein sequences with that of pYJ016 was higher than $98.2 \%$ for TraD and $98.3 \%$ for TraI.

\section{Ribotyping}

Representative strains of the different plasmid profiles were analysed by ribotyping; the results are shown in Fig. 4 . With the exception of biotype 3 strains, no correspondence between ribopattern and plasmid profile was observed:

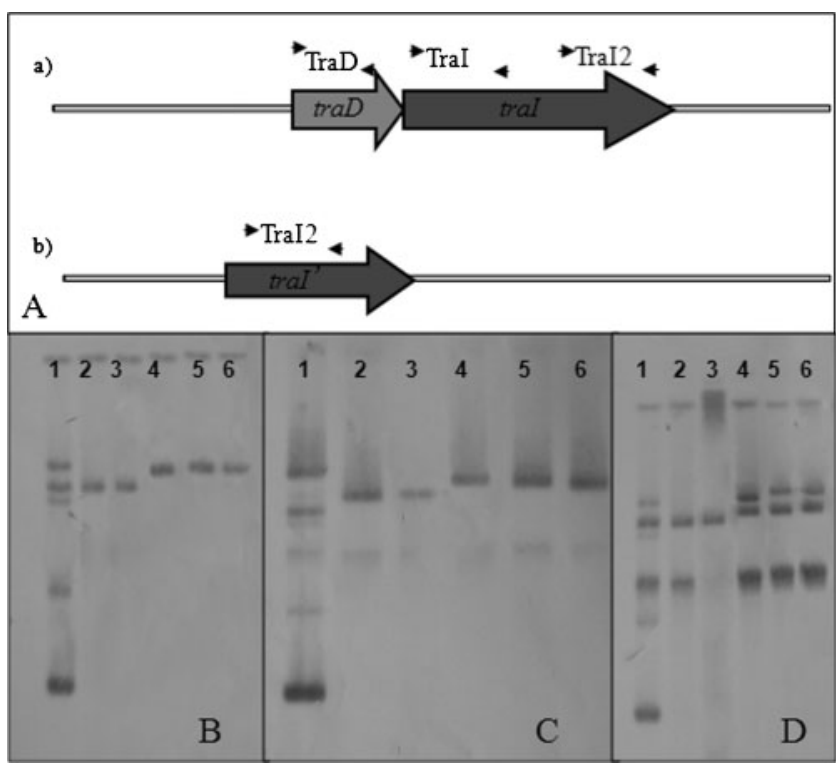

Fig. 3. Southern hybridization results for traD, tral and tral2. (A) Diagram of the probe design to detect plasmids with truncated tral: a) conjugative plasmid; b) virulence plasmid. (B) Southern hybridizations of pre-stained 39R861 (lane 1), YJ016 (2), 11028 (3), CECT 4604 (4), A14 (5) and 95-8-162 (6) with probe TraD (B), probe Tral (C) and probe Tral2 (D). 


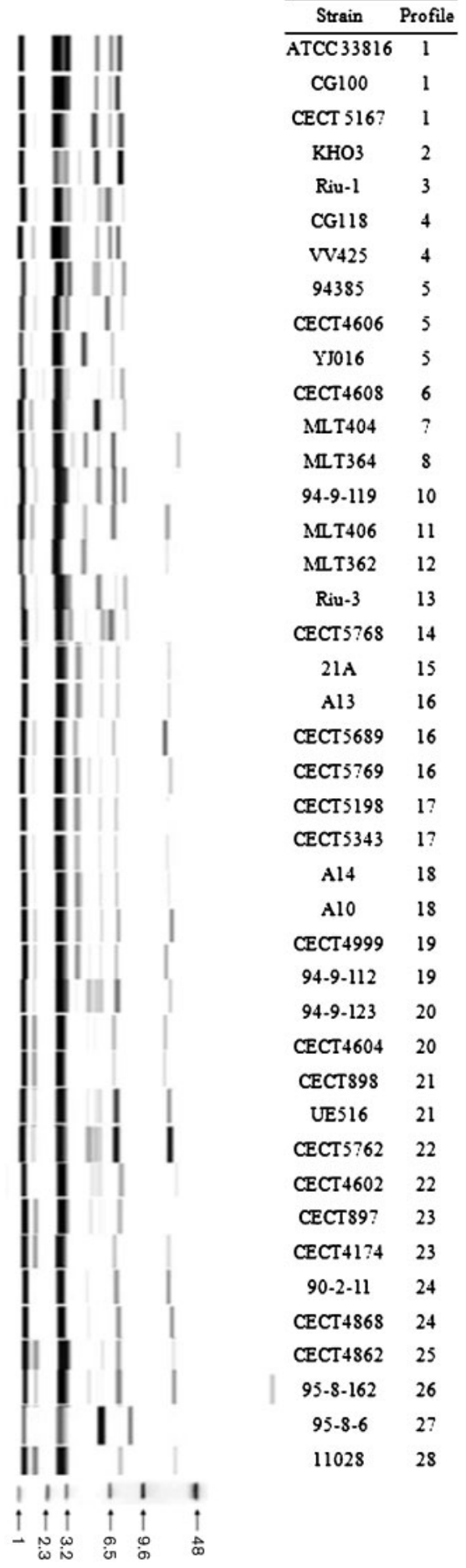

Fig. 4. Ribotypes obtained with Hindlll for representative strains of each plasmid profile of $V$. vulnificus.

different ribopatterns were shown by strains belonging to the same plasmid profile group and, conversely, a common ribopattern was generated by strains belonging to different plasmid profile groups (Fig. 4).

\section{DISCUSSION}

The species $V$. vulnificus is one of the vibrio species whose genome has been sequenced. The two sequenced strains show a high degree of chromosomal similarity, which does not reflect the high degree of variability and plasticity displayed by a species able to colonize hosts as different as humans and fish and act as both pathogen and commensal microbiota. In contrast to the homology of their chromosomes, the two strains differ in their plasmid content, which is of particular interest given that previous studies have reported a general lack of extrachromosomal elements within this species. The genetic homogeneity of these two strains is probably related to the characteristics of the isolates chosen for this study (both biotype 1 human isolates were recovered from human blood from two proximal countries in South-east Asia: Taiwan and Korea); greater chromosomal variation is to be expected by sequencing strains from more diverse sources. Despite this fact, our results suggest that plasmids could play a role in generating diversity within the species.

Our work reinforces the putative role of plasmids in the evolution and environmental adaptation of $V$. vulnificus. First, most of the strains analysed, especially those belonging to biotypes 2 and 3, harboured plasmids and almost 30 different plasmid profiles were found in a total of 112 strains. These plasmid profiles were biotype- or serovar-specific, since no profile was shared by strains of different biotypes or by strains of different serovars. In contrast, no correlation was found between the origin of a strain and its plasmid profile, since the same profile was shared by clinical and environmental strains, and by strains isolated from Asia, Europe or America. Almost half of the biotype 1 strains lacked plasmids, partially confirming previous work performed with clinical and environmental biotype 1 strains, which reported a general lack of extrachromosomal elements within the species (Davidson \& Oliver, 1986). Most of the remaining biotype 1 strains harboured a putative conjugative plasmid of a molecular size similar to that of pYJ016 (Chen et al., 2003). In fact, the sequence analysis of a fragment of traD and traI from this putative conjugative plasmid revealed that the gene fragments are almost identical to those of pYJ016, and thus all these plasmids probably belong to the same family of Fplasmids.

In relation to biotypes 2 and 3, $100 \%$ of the strains carried plasmids. Interestingly, all biotype 2 strains, regardless of serovar, carried the virulence plasmid, a plasmid recently described in two serovar E isolates (Lee et al., 2008). These two plasmids (pC4602-2 and pR99) have been sequenced and display $92 \%$ homology, the main difference between them being a mazEF operon (coding for a toxin/antitoxin system) present in pR99 and absent in pC4602-2 (Lee et al., 2008). Half the plasmid ORFs were annotated as hypothetical and, of the remainder, an $r t x$ gene cluster and the ORF vep07, which contains seq 51 and a part of seq25, were highlighted. Mutations in this gene produced a significant 
reduction in virulence for eels and survival in eel blood, which suggests that this gene codes for a novel virulence factor (Lee et al., 2008).

Our results confirm the importance of vep07 for virulence, since (i) mutations that produced a change in this gene resulted in a loss of eel virulence and (ii) the homology of the protein inferred by comparison of sequences of vep07 in different strains from different origins and serovars was between 99.7 and $100 \%$.

Interestingly, almost $90 \%$ of biotype 2 strains also carried a putative conjugative plasmid, similar in size to the conjugative plasmid pC4602-1. Plasmid pC4602-1 displays a high sequence similarity to pYJ016, in terms of both DNA sequence and gene organization (Lee et al., 2008). Sequence analysis of a fragment of the traD and traI genes performed in our study confirms that biotype 2 plasmids are of the same family of F-plasmids as pYJ016. These plasmids have been demonstrated to be essential for transmission of the virulence plasmid by means of conjugation experiments (Lee et al., 2008). In those experiments the virulence plasmid was transmitted with a frequency of $3.9 \%$ and almost a third of the transconjugants carried only the virulence plasmid. In our study, $6.9 \%$ of the biotype 2 strains possessed only the virulence plasmid, which is in accordance with the study of Lee et al. (2008), and supports the hypothesis that the conjugative plasmid plays an essential role in the natural transmission of the virulence plasmid.

In relation to biotype 3, all strains showed an identical plasmid profile, and furthermore, all contained a putative conjugative plasmid identical in size to pYJ016. The sequence analysis of traD and traI revealed that the biotype 3 conjugative plasmid probably belongs to the same family of F-plasmids as that of YJ016.

In addition, we examined the relationship between chromosomal and plasmid typing by comparing ribopatterns and plasmid profiles. No correspondence was found between biotype 1 and 2 strains, since the same plasmid profile was presented by strains with different ribopatterns and, conversely, different plasmid profiles were associated with the same ribopattern. In the case of biotype 3 strains, the strains showed the same ribopattern and the same plasmid profile, which reinforces the hypothesis that this biotype constitutes a clonal complex formed by genetically identical strains (Bisharat et al., 2007b). Previous ribotyping studies in $V$. vulnificus have suggested that this technique could be used as an epidemiological tool to distinguish clones within the species. Our results demonstrate that this technique should be used in combination with plasmid profile determination, which allows strains of the same ribopattern to be distinguished. Conversely, ribotyping enables strains of the same plasmid profile to be distinguished.

In summary, $V$. vulnificus possesses plasmids. The virulence plasmid is limited to biotype 2 strains and is absolutely essential for eel virulence, whereas conjugative plasmids of the same family are widely distributed among the three biotypes and could have contributed to the transmission of the virulence plasmid. All these plasmids probably play an important role in environmental adaptation and plasticity of the species.

\section{ACKNOWLEDGEMENTS}

This work has been financed by grants AGL2005-04688 (cofinanced with FEDER funds), AGL2008-03977 and PET2005-0053 from the Spanish Ministry for Education and Science and grant MTKD-CT-2004-0145019 from the European Union. The authors also thank SCSIE of the University of Valencia for technical support in determining the sequences.

\section{REFERENCES}

Amaro, C. \& Biosca, E. G. (1996). Vibrio vulnificus biotype 2, pathogenic for eels, is also an opportunistic pathogen for humans. Appl Environ Microbiol 62, 1454-1457.

Amaro, C., Biosca, E. G., Fouz, B. \& Garay, E. (1992). Electrophoretic analysis of heterogeneous lipopolysaccharides from various strains of Vibrio vulnificus biotypes 1 and 2 by silver staining and immunoblotting. Curr Microbiol 25, 99-104.

Amaro, C., Biosca, E. G., Fouz, B., Alcaide, E. \& Esteve, C. (1995). Evidence that water transmits Vibrio vulnificus biotype 2 infections to eels. Appl Environ Microbiol 61, 1133-1137.

Ausubel, F. M., Brent, R., Kingston, R. E., Moore, D. D., Seidman, J. G., Smith, J. A. \& Struhl, K. (2007). Current Protocols in Molecular Biology. New York: Wiley.

Biosca, E. G., Oliver, J. D. \& Amaro, C. (1996). Phenotypic characterization of Vibrio vulnificus biotype 2, a lipopolysaccharidebased homogeneous $\mathrm{O}$ serogroup within Vibrio vulnificus. Appl Environ Microbiol 62, 918-927.

Bisharat, N., Agmon, V., Finkelstein, R., Raz, R., Ben-Dror, G., Lerner, L., Soboh, S., Colodner, R., Cameron, D. N. \& other authors (1999). Clinical, epidemiological, and microbiological features of Vibrio vulnificus biogroup 3 causing outbreaks of wound infection and bacteraemia in Israel. Israel Vibrio Study Group. Lancet 354, 14211424.

Bisharat, N., Amaro, C., Fouz, B., Llorens, A. \& Cohen, D. I. (2007a). Serological and molecular characteristics of Vibrio vulnificus biotype 3: evidence for high clonality. Microbiology 153, 847-856.

Bisharat, N., Cohen, D. I., Maiden, M. C., Crook, D. W., Peto, T. \& Harding, R. M. (2007b). The evolution of genetic structure in the marine pathogen, Vibrio vulnificus. Infect Genet Evol 7, 685-693.

Chen, C. Y., Wu, K. M., Chang, Y. C., Chang, C. H., Tsai, H. C., Liao, T. L., Liu, Y. M., Chen, H. J., Shen, A. B. \& other authors (2003). Comparative genome analysis of Vibrio vulnificus, a marine pathogen. Genome Res 13, 2577-2587.

Davidson, L. S. \& Oliver, J. D. (1986). Plasmid carriage in Vibrio vulnificus and other lactose-fermenting marine vibrios. Appl Environ Microbiol 52, 211-213.

Felsenstein, J. (1985). Confidence limits on phylogenies: an approach using the bootstrap. Evolution 39, 783-791.

Fouz, B., Roig, F. J. \& Amaro, C. (2007). Phenotypic and genotypic characterization of a new fish-virulent Vibrio vulnificus serovar that lacks potential to infect humans. Microbiology 153, 1926-1934.

Kim, Y. R., Lee, S. E., Kim, C. M., Kim, S. Y., Shin, E. K., Shin, D. H., Chung, S. S., Choy, H. E., Progulske-Fox, A. \& other authors (2003). 
Characterization and pathogenic significance of Vibrio vulnificus antigens preferentially expressed in septicemic patients. Infect Immun 71, 5461-5471.

Lee, C. T., Amaro, C., Sanjuan, E. \& Hor, L. I. (2005). Identification of DNA sequences specific for Vibrio vulnificus biotype 2 strains by suppression subtractive hybridization. Appl Environ Microbiol 71, 5593-5597.

Lee, C. T., Amaro, C., Wu, K. M., Valiente, E., Chang, Y. F., Tsai, S. F., Chang, C. H. \& Hor, L. I. (2008). A common virulence plasmid in biotype 2 Vibrio vulnificus and its dissemination aided by a conjugal plasmid. J Bacteriol 190, 1638-1648.

Lewin, A., Bert, B., Dalsgaard, A., Appel, B. \& Hoi, L. (2000). A highly homologous $68 \mathrm{kbp}$ plasmid found in Vibrio vulnificus strains virulent for eels. J Basic Microbiol 40, 377-384.

Macrina, F. L., Kopecko, D. J., Jones, K. R., Ayers, D. J. \& McCowen, S. M. (1978). A multiple plasmid-containing Escherichia coli strain: convenient source of size reference plasmid molecules. Plasmid 1, 417-420.

Oliver, J. D. (2005). Wound infections caused by Vibrio vulnificus and other marine bacteria. Epidemiol Infect 133, 383-391 (Review).

Oliver, J. D. (2006). Vibrio vulnificus. In Biology of Vibrios, pp. 349366. Edited by F. L Thompson, B. Austin \& F. L. Thompson. Washington, DC: American Society for Microbiology Press.

Reed, L. J. \& Muench, H. (1938). A simple method of estimating fifty percent endpoints. Am J Hyg 27, 493-497.
Saitou, N. \& Nei, M. (1987). The neighbor-joining method: a new method for reconstructing phylogenetic trees. Mol Biol Evol 4, 406425.

Tamura, K., Dudley, J., Nei, M. \& Kumar, S. (2007). MEGA4: molecular evolutionary genetics analysis (MEGA) software version 4.0. Mol Biol Evol 24, 1596-1599.

Threlfall, E. J., Rowe, B., Ferguson, J. L. \& Ward, L. R. (1986). Characterization of plasmids conferring resistance to gentamicin and apramycin in strains of Salmonella typhimurium phage type 204c isolated in Britain. J Hyg (Lond) 97, 419-426.

Tison, D. L., Nishibuchi, M., Greenwood, J. D. \& Seidler, R. J. (1982). Vibrio vulnificus biogroup 2: new biogroup pathogenic for eels. Appl Environ Microbiol 44, 640-646.

Valiente, E., Lee, C. T., Lamas, J., Hor, L. \& Amaro, C. (2008). Role of the virulence plasmid pR99 and the metalloprotease Vvp in resistance of Vibrio vulnificus serovar E to eel innate immunity. Fish Shellfish Immunol 24, 134-141.

Zhou, C., Yang, Y. \& Jong, A. Y. (1990). Mini-prep in ten minutes. Biotechniques 8, 172-173.

Zuckerkandl, E. \& Pauling, L. (1965). Evolutionary divergence and convergence in proteins. In Evolving Genes and Proteins, pp. 97-166. Edited by V. Bryson \& H. J. Vogel. New York: Academic Press.

Edited by: L. S. Frost 